of the fat or starch in the blanched cell, nor the formation of grape-sugar or dextrin: he therefore concludes that the products of the oxidation of the chlorophyll are given off in the gaseous form. In the second place he concludes that the changes produced in the protoplasmic cell-contents are the direct effects of the photochemical action of light. That they are not due to the presence of the products of the decomposed chlorophyll is shown by the fact that they may be observed equally well in cells which do not contain chlorophyll, such as the stinging hairs of the nettle, \&c. This being the case, he infers that they too are produced by a process of combustion. The final conclusion to which he comes is that chlorophyll exercises a protective influence over the protoplasmic cell-contents by absorbing the actinic rays of the spectrum, thus diminishing the combustion (respiration) going on in the cell; that it is in fact the regulator of the respiration.

In another series of experiments Prof. Pringsheim endeavours to determine what are the substances which become oxidised in the process of respiration. He finds in all chlorophyll-containing cells, a substance which can be best extracted by immersing the parts-leaves for instance-in dilute hydrochloric acid for several hours. This substance, to which he gives the name of hypochlorin or hypochromyl, is of an oily nature; it is probably a hydrocarbon which consists only of carbon and of hydrogen, or one which contains oxygen also in its molecule, but in smaller proportion than the carbohydrates; it is soluble in alcohol, ether, turpentine, and benzol, but insoluble in water and in solutions of neutral salts; it occurs in long, red-brown, crystalline needles which soon harden after extraction, into an imperfectly crystalline mass of resinous or waxy consistence. It is readily oxidisable, as is shown by the fact that it disappears from the cell on exposure to intense light in an atmosphere containing oxygen, even sooner than the chlorophyll. Prof. Pringsheim is of opinion that this substance is the first product of the assimilation of the chlorophyll-corpuscle, and that starch and oil are subsequently formed from it by oxidation.

Applying these views to the life of the cell under ordinary conditions, the changes going on in the cell when exposed in the air to sunlight would be somewhat as follows: the general protoplasm would undergo some amount of oxidation, but not so much as to materially diminish its quantity or affect its properties; in the chlorophyll-corpuscles, oxidation would be either entirely arrested in consequence of the absorption of the actinic rays by the green colouring-matter, or at least so much diminished that the synthesis of the elements of water and carbonic acid to form hypochlorin could take place.

Since this paper is stated to be a merely provisional account of these very interesting experiments, it is hardly fair to submit it to a detailed criticism : it will be better to wait until the publication of the more complete account which Prof. Pringsheim promises in an early number of his Jahrbiucher. All that will be attempted at present is to indicate some of the principal difficulties which beset the acceptance of these new views. For instance, exception may be taken to the view that chlorophyll, when exposed to intense light is oxidised into gaseous bodies. It is well known that an alcoholic solution of chlorophyll, when exposed to sunlight in the presence of air, becomes oxidised and assumes a pale yellow colour; it may be that this also takes place in the chlorophyll-corpuscles, the yellow colour being hardly distinguishable on account of the smallness of the quantity which is present. Again, it will doubtless have occurred to every reader of this paper that hypochlorin may be nothing more than the wax which has long been known to exist in considerable quantity in chlorophyll-corpuscles. But the main difficulty has reference to the protective functions which Prof. Pringsheim ascribes to chlorophyll.
Admitting that the changes described above as occurring in the protoplasmic cell-contents are really the results of excessive oxidation consequent upon exposure to the intense light, it is evident that they are effected less quickly than the oxidation of the chlorophyll itself; that is to say that, ceteris paribus, the chlorophyll is more readily oxidised than the protoplasm. This being the case, it is not easy to understand how the former can efficiently protect the latter from the oxidising influence of light and regulate its respiration. This difficulty might perhaps be met by the suggestion that fresh supplies of chlorophyll are continually being formed, but we have no knowledge yet at present of any such continual formation of chlorophyll; on the contrary, it is a well-established fact that when once the chlorophyll of a corpuscle is oxidised, it does not regain its green colour.

It might perhaps be possible to obtain some further knowledge on this subject by observing the effects produced in cells by the action of strong light falling upon them, in some cases, directly, in others, after having passed through a solution of chlorophyll which would be renewed from time to time if necessary. If it were found, that, in the latter case, the cells remained uninjured whereas in the former they soon died, some important evidence in favour of Prof. Pringsheim's views would be obtained. It might then be possible to extend these experiments and to bring about the formation of starch from carbonic acid and water in the cells of fungi, and even of animals, for Mr. Geddes' interesting observations on planarians show that animal as well as vegetable protoplasm is capable of effecting this synthesis.

SYDNEY H. VINES

\section{THE CAMBRIDGE NATURAL SCIENCES}

WOULD science suffer by the division of the second part of the tripos into a non-biological and a biological division which might be taken in successive weeks with separate examiners?

Let us make sure that in future geologists know well their chemistry and physics, and insist on all biologists knowing how to work their microscope well. Perhaps some geologists will shrink from a division of subjects.; and consider that every geologist should know palæontology well. But the study of fossil plants and animals is surely a part of systematic botany and zoology; in fact, geology and palæontology would gain by being separated, so far as the one is physical, stratigraphical, petrological, and mineralogical, or the other truly biological. The knowledge of fossils as characterising a "formation" is not a biological subject ; a man may recognise fossils well enough for geological purposes who knows little of zoology properly so called. Biology suffers greatly from the want of palæontologists as distinct from physical geologists and petrologists. How many men are there who would agree that biology ("the study of things living or that have lived") is very difficult to separate from physical and non-biological subjects for examinational purposes? Let us acknowledge that it is more necessary that, at the commencement of his scientific career, a man should be known and recognised as a well-educated biologist than as a vegetable anatomist, or a palæontologist, or an embryologist. Every man seeking biological honours may find sufficiently little chemistry and physics in the first part of the natural sciences tripos not to daunt him, if he is capable of research. Surely it is better to secure a man's general physico chemical knowledge if he is to be a geological surveyor of the first rank, and also train him in elementary biology, than to encourage too early specialisation.

My proposal is that in the second part of the natural sciences tripos four or more examiners should be specially chosen to set and approve the biological questions, and 
four or more, the physico-chemical and geological questions; that the latter should have a separate class-list and days of examination, with four written papers of three rows each, and a practical examination ; and that the biological examination should have four papers and be in other respects similarly conducted, letting no special marks of distinction be given. Few first-rate candidates would desire to take both these examinations, and if they desire further distinction in particular subjects, original work in research or authorship, is surely the best test; and the University might subsequently give to competent men degrees in science which now it unfairly cannot give; the degree of Doctor of Science should be given to men qualified to be University Readers or Professors in Science.

Mr. Hillhouse, of Trinity, the Assistant Curator of the Cambridge Herbarium, and one of the editors of the Cambridge Review, in an article last week, admits that which many promoters of learning might think a sign of unrest and indecision, rather than of real growth, namely, that the regulations issued by the Board of Natural Sciences Studies must be very mutable, and continually need revision. As to the argument for human anatomy as such receiving a prominent place in a tripos, $\mathrm{Mr}$. Hillhouse says it rests on the fallacy that men are likely to study a subject with more interest if it is made a subject of a tripos, than if it is included in the M.B. But, his experience is, the man who will not work for his M.B. will surely not work for his tripos; if anything, he will work better for M.B. than tripos.

The University of London, having for a long time required all candidates for the degree of B.Sc. to pass in elementary mathematics, physics, geology, palæontology, and the other biological sciences, as well as logic, has now reverted to the wiser plan of examining at its Ist B.Sc. in elementary mathematics, physics, inorganic chemistry, and elementary biology, and at the degree examination (for B.Sc.), giving the degree for passing in three out of nine divisions of sciences, so that a biological student may, if he chooses, enter for a very clearly-detined examination in botany, zoology, and physiology. The Cambridge man will then soon prefer the B.Sc. Lond., with the subsequent possibility of a doctorship in science, given for thorough attainment in the special subject of his life-study and teaching, unless biology receives fair play at Cambridge. Why is it that Martin, Hartog, Marshall, and Vines havetaken their D.Sc. (Lond.), to mention biologists only? It is surely not that they are devoted to examinations, but that Cambridge was not yet able to give them the distinction in their chosen subjects which they were entitled to demand. Biology, worthy of the name, is still to a very considerable extent proscribed or suspected in Cambridge. In a future age how strange a survival of prejudice this will seem.

G. T. BETTANY

\section{THE PLANETS OF THE SEASON}

\section{SATURN}

$\mathrm{W}$

E recently called the attention of our astronomical readers to that noble planet, the captain of our celestial guard, those three that keep the mid-watch of the night in an imposing order that may not return for ages; at distances nearly equal, and in a line not widely deviating from a great circle of the sphere. Saturn, the next in position, may now be the subject of a cursory notice.

The aspect of this most interesting of the planets is at the present time singularly elegant and attractive. The relief, however, is delicate, and the details not conspicuous; but though the presentation may be less adapted for a close scrutiny than that of either the full opening or the evanescent pbasis of the ring, its examination will not fail to reward the careful observer.
Schröter had a true insight into the pervading character of the universe when he described it as uniform in plan, with an endless variety in detail. Such is evidently the case with the planetary system. We find everywhere arrangements in part closely parallel or even identical with those most familiar to us, in part so rapidly divergent that the connecting analogies are strained, and thin away, as it were, till the bond of union can be traced no longer. Saturn is a complete instance of this. The dependence on the great central ruler, the spherical form, the polar flattening, the rotation on an inclined axis, the accompaniment of an atmosphere-all correspond with our own; while the differences, not only in magnitude, but in density and the force of gravity, are so great that we cannot even guess at the component materials. We endeavoured lately to point out how limited is our knowledge of Jupiter, though in various ways favourably circumstanced for observation; but on Saturn, with the exception of his change of seasons, we should find ourselves still greater strangers; and the terrestrial analogies that aided us so little there would here be of still less service. Every difficulty is magnified by the vast increase of distance and defalcation of light ; we can only record what we see, and much of that is neither familiar nor intelligible.

It is easy, however, to perceive a strong general resemblance between these two great globes, not only in gigantic dimensions, want of density, and velocity of rotation, but in various atmospheric characteristics, such as parallelism of direction (sometimes, according to Herschel I., not quite equatorial on Saturn), contrasted colouring, and the occasional formation of bright and obscure patches. And yet in one main feature there is a very marked dissimilarity-the position of their axes. In this one point Saturn, after a decided interruption in the series, reverts to the type of the earth and Mars. And it is scarcely conceivable that the presence or absence of a change of seasons should not be strongly felt in its effects. One result, however, which might on a superficial view have been expected, is absent from Saturn. There is no luminous deposit around the poles, which, on the contrary, are often more dusky than the equatorial regions, and this alone would infer a different atmospheric constitution from our own, even if we left out of sight the consideration that such might well be expected when the subjacent materials are as light as cork, and the whole globe would float high out of water. But for this curious deviation from regular sequence-a kind of deviation so remarkable and so significant in the planetary system -we should have remarked as complete an analogy between Jupiter and Saturn as that which is believed to obtain between the Earth and Mars.

The changes, however, in the atmosphere of Saturn are not usually so conspicuous as those on Jupiter; nor is this to be wondered at, when we consider its inferior brilliancy at a distance measured by hundreds of millions of miles. The equatorial zone is usually represented as of prominent and unvaried brightness, and the dusky belts differ much in depth and arrangement at different times. Luminous and dark patches, though not common, are far from being unknown. The white equatorial spot, resolving itself ultimately into a streak, which was observed by Hall in 1876 , though not, as has been asserted, an unprecedented, was a very remarkable instance of the former class, as one perceived by Herschel I., ninety-six years before, had been of the latter. This dusky spot was situated near the limb, where on Jupiter it would presumably have been invisible; yet much could not be inferred from this solitary observation, nor from that of Chacornac on the transit of the largest satellite, which showed a limb more luminous than the centre of the disk. Everything of this kind should be noted, but nothing pressed into the service of a foregone theory.

The flattening of the sphere at the equator, as well as 